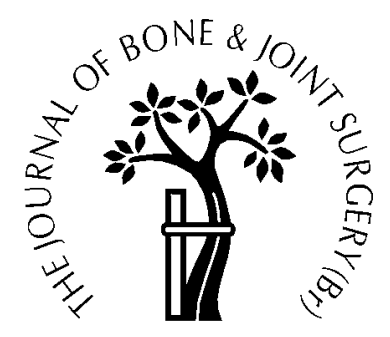

\title{
Fluconazole-impregnated beads in the management of fungal infection of prosthetic joints
}

\author{
A. S. W. Bruce, R. M. Kerry, P. Norman, I. Stockley \\ From the Northern General Hospital NHS Trust, Sheffield, England
}

\section{We report two cases of fungal infection of prosthetic joints which were successfully treated by the incorporation of fluconazole into polymethylmethacrylate beads inserted at the time of debridement.}

J Bone Joint Surg [Br] 2001;83-B:183-4.

Received 12 June 2000; Accepted after revision 26 September 2000

To our knowledge, only 25 cases of fungal infection around prostheses have been reported. ${ }^{1-18}$ There seems to be general agreement about the need for excision arthroplasty and prolonged intravenous administration of antifungal agents, usually amphotericin B. Staged reimplantation was attempted in six patients and was successful in four. ${ }^{2,3,12-14}$ Eventual mycological cure may have been achieved, although the follow-up was less than a year in half of the cases. We incorporated fluconazole into polymethylmethacrylate (PMMA) in the form of beads as part of a two-stage surgical procedure in two patients. Infection of the joint by Candida was successfully eradicated in both.

\section{Case reports}

Case 1. A 51-year-old woman who had had a right total hip replacement in 1984 presented with hip pain in 1987. A biopsy, in 1990, revealed infection with Candida parapsilosis. In August 1991, a first-stage exchange procedure was undertaken with removal of all foreign material and infected tissue. Candida parapsilosis was again grown from the specimens. Methylmethacrylate beads were prepared by adding $2 \mathrm{~g}$ of fluconazole powder to one mix of Palacos R bone cement (Schering Plough Ltd, Mildenhall, UK), and made into chains. These were inserted into the acetabulum and femoral shaft before the wound was closed

A. S. W. Bruce, FRCS, Senior House Officer

R. M. Kerry, FRCS Orth, Consultant Orthopaedic Surgeon

P. Norman, FRCPath, Consultant Medical Microbiologist

I. Stockley, FRCS, Consultant Orthopaedic Surgeon

Northern General Hospital NHS Trust, Herries Road, Sheffield S5 7AU, UK.

Correspondence should be sent to Mr I. Stockley.

(c)2001 British Editorial Society of Bone and Joint Surgery 0301-620X/01/211444 \$2.00 over deep and superficial drains. Four days later treatment with oral fluconazole ( $200 \mathrm{mg}$ twice daily) was started. The levels of fluconazole were measured in the fluid in the drain for six days after operation (Fig. 1). Specimens of tissue taken in February 1992, when the beads were removed, were sterile. In June 1992, a prosthesis was reimplanted with fluconazole again added to the cement. Specimens of tissue again did not grow any organisms. Oral fluconazole was not administered. There has been no evidence of recurrence of infection for seven years.

Case 2. A 68-year-old woman underwent a replacement of the femoral head for a subcapital hip fracture in 1994. In 1996, the implant was clinically and radiologically loose. Aspirate from the hip grew Candida albicans. First-stage exchange surgery was carried out as described above and infection with Candida albicans confirmed. Again $2 \mathrm{~g}$ of fluconazole were placed in 'home-made' Palacos R beads, and oral fluconazole was administered by the same regime. The levels of fluconazole measured from the deep and superficial drains are shown in Figure 2. Reimplantation was undertaken three months later without an intervening biopsy or administration of systemic fluconazole. Tissue specimens were sterile. The patient died more than four years later with no sign of recurrence of the infection, either clinically or radiologically.

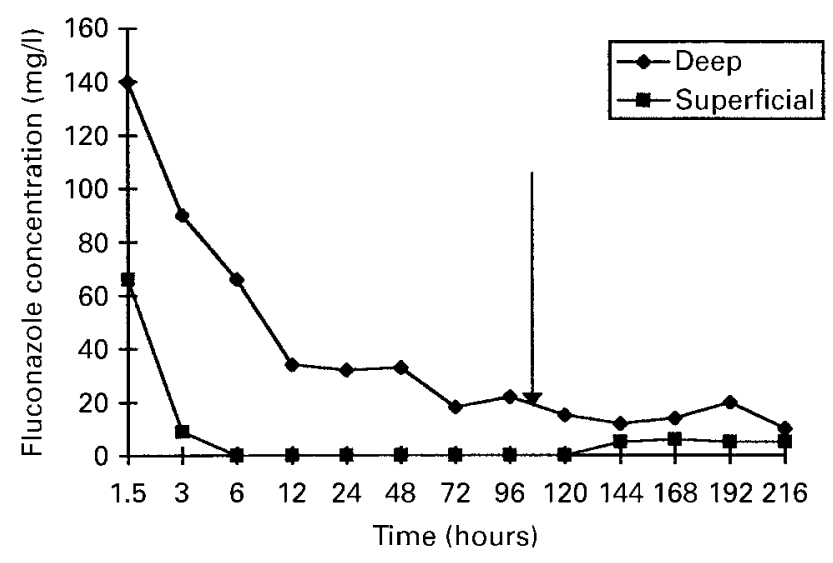

Fig. 1

Case 1. The fluconazole concentration in the fluid from the deep and superficial drains (arrow indicates the commencement of oral fluconazole). 


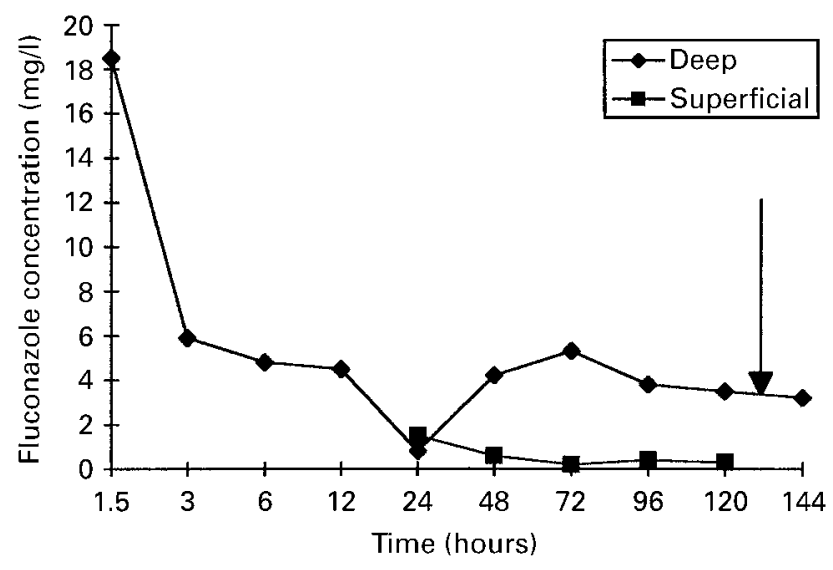

Fig. 2

Case 2. The fluconazole concentration in the fluid from the deep and superficial drains (arrow indicates the commencement of oral fluconazole).

\section{Discussion}

In the management of fungal infection around prostheses it has been stated that removal of the prosthesis and prolonged administration of amphotericin B are essential in order to eradicate the infection. ${ }^{13,19}$ An antifungal drug which remains effective after incorporation into PMMA bone cement may be a useful alternative. ${ }^{19}$

Many heat-stable antibiotics elute from PMMA cement in a predictable manner and Palacos cement has elution characteristics which seem particularly favourable. ${ }^{20,21}$ The addition of many antibiotics in a dose adequate enough to give high local levels with very low systemic levels, does not seem to have a significant effect on the mechanical properties of cement. Preliminary studies on the in vitro elution of fluconazole from Palacos $\mathrm{R}$ at our hospital confirmed that detectable fungicidal levels could be obtained for several days. Figure 1 shows that the levels obtained in the deep tissues in our first patient (case 1) were very high. Oral fluconazole was prescribed after the first four days as a precautionary measure because the in vitro study had demonstrated a significant fall in concentration after this period. The levels in the superficial drain rose and were reasonably constant at about $5.5 \mathrm{mg} / \mathrm{l}$. There was a different pattern in our second patient (Fig. 2). Very high levels were obtained initially and were maintained at approximately $5 \mathrm{mg} / \mathrm{l}$ for several days. The level in the superficial drain was low and was not raised significantly by the oral administration of fluconazole after four days. The total amount of fluconazole eluted was $21 \mathrm{mg}$ in case 1 and $13.9 \mathrm{mg}$ in case 2 . The volume of drainage in the second patient was significantly higher than in the first $(4.11 \vee 1.01)$, but this does suggest that predictably high levels around the joint cannot be guaranteed with orally administered fluconazole. The high local levels obtained from impregnated PMMA seem to be predictable and reliable, and oral supplementation may not be required, as has been our experience with pyogenic deep sepsis.

No benefits in any form have been received or will be received from a commercial party related directly or indirectly to the subject of this article.

\section{References}

1. MacGregor RR, Schimmer BM, Steinberg ME. Results of combined amphotericin B-5-fluorocytosine therapy for prosthetic knee joint infected with Candida parapsilosis. J Rheumatol 1979;6:451-5.

2. Goodman JS, Seibert DG, Reahl GE, Geckler RW. Fungal infection of prosthetic joints: a report of two cases. J Rheumatol 1983;10:494-5.

3. Younkin S, Evarts CM, Steigbigel RT. Candida parapsilosis infection of a total hip-joint replacement: successful reimplantation after treatment with amphotericin B and 5-fluorocytosine: a case report. $J$ Bone Joint Surg [Am] 1984;66-A:142-3.

4. Lim EVA, Stern PJ. Candida infection after implant arthroplasty: a case report. J Bone Joint Surg [Am] 1986;68-A:143-5.

5. Lichtman EA. Candida infection of a prosthetic shoulder joint. Skeletal Radiol 1983;10:176-7.

6. Koch AE. Candida albicans infection of a prosthetic knee replacement: a report and review of the literature. J Rheumatol 1988;15:362-5.

7. Iskander MK, Khan MA. Candida albicans infections of a prosthetic knee replacement. J Rheumatol 1988;15:1594-5.

8. Levine M, Rehm SJ, Wilde AH. Infection with Candida albicans of a total knee arthroplasty: case report and review of the literature. Clin Orthop 1988;226:235-9.

9. Lambertus M, Thordarson D, Goetz MB. Fungal prosthetic arthritis: presentation of 2 cases and review of the literature. Rev Infect Dis 1988;10:1038-43.

10. Paul J, White SH, Nicholls KM, Crook DW. Prosthetic joint infection due to Candida parapsilosis in the UK: case report and literature review. Eur J Clin Microbiol Infect Dis 1992;11:847-9.

11. Simonian PT, Brause BD, Wickiewicz TL. Candida infection after total knee arthroplasty: management without resection or amphotericin B. J Arthroplasty 1997;12:825-9.

12. Evans RP, Nelson CL. Staged reimplantation of a total hip prosthesis after infection with Candida albicans: a report of two cases. J Bone Joint Surg [Am] 1990;72-A:1551-3.

13. Tunkel AR, Thomas CY, Wispelwey B. Candida prosthetic arthritis: report of a case treated with fluconazole and review of the literature. Am J Med 1993;94:100-3.

14. Hennessy MJ. Infection of a total knee arthroplasty by Candida parapsilosis: a case report of successful treatment by joint reimplantation with a literature review. Am J Knee Surg 1996;9:133-6.

15. Brooks DH, Pupparo F. Successful salvage of a primary total knee arthroplasty infected with Candida parapsilosis. J Arthroplasty 1998;13:707-12.

16. Wada M, Baba H, Imura S. Prosthetic knee Candida parapsilosis infection. J Arthroplasty 1998;13:479-82.

17. Cushing RD, Fulgenzi WR. Synovial fluid levels of fluconazole in a patient with Candida parapsilosis prosthetic joint infection who had an excellent clinical response. $J$ Arthroplasty 1997;12:950.

18. Fukasawa N, Shirakura K. Candida arthritis after total knee arthroplasty: a case of successful treatment without prosthesis removal. Acta Orthop Scand 1997;68:306-7.

19. Darouiche RO, Hamill RJ, Musher DM, Young EJ, Harris RL. Periprosthetic Candida infections following arthroplasty. Rev Infect Dis 1989;11:89-96.

20. Marks KE, Nelson CL, Lautenschlager EP. Antibiotic-impregnated acrylic bone cement. J Bone Joint Surg [Am] 1976;58-A:358-64.

21. Elson RA, Jephcott AE, McGechie DB, Verettas D. Antibiotic loaded acrylic cement. J Bone Joint Surg [Br] 1977;59-B:200-5. 